\title{
Rejection from the Disability Insurance Program and Dependency on Social Support
}

\author{
Susan E. Chen
}

Project \#: UM12-16 



\title{
Rejection from the Disability Insurance Program and Dependency on Social Support
}

\author{
Susan E. Chen \\ University of Alabama \\ September 2014 \\ Michigan Retirement Research Center \\ University of Michigan \\ P.O. Box 1248 \\ Ann Arbor, MI 48104 \\ www.mrrc.isr.umich.edu \\ (734) 615-0422
}

\section{Acknowledgements}

This work was supported by a grant from the Social Security Administration through the Michigan Retirement Research Center (Grant \# 5 RRC08098401-04-00). The findings and conclusions expressed are solely those of the author and do not represent the views of the Social Security Administration, any agency of the Federal government, or the Michigan Retirement Research Center. 


\title{
Rejection from the Disability Insurance Program and Dependency on Social Support
}

\begin{abstract}
Recent studies find that many workers do not return to the labor force after their applications for Disability Insurance (DI) are denied. It is, therefore, important to understand how this group funds their consumption. This paper uses the Survey of Income and Program Participation linked to administrative data to examine the social support participation behavior of rejected applicants. By following cohorts of individuals from 10 years before to 10 years after filing for DI, this paper shows that rejected DI applicants are at most 10 percent more likely to depend on social support programs than healthy workers. More general models show that at the time of application rejected applicants are 25 percent more likely to depend on social support programs than healthy workers. These effects decrease across time, but up to 10 years after filing, rejected DI applicants are still up to 12 percent more likely to depend on social support programs. These are the same levels of social support participation exhibited by DI beneficiaries. While rejecting more DI applicants may reduce DI outlays, these results suggest that rejected applicants are more likely to depend on other federally funded assistance programs to fund their early retirement.
\end{abstract}

\section{Citation}

Chen , Susan E. (2014). "Rejection from the Disability Insurance Program and Dependency on Social Support.” Michigan Retirement Research Center (MRRC) Working Paper, WP 2014-305. http://www.mrrc.isr.umich.edu/publications/papers/pdf/wp305.pdf

\section{Authors’ Acknowledgements}

Financial support from the Michigan Retirement Research Center is gratefully acknowledged. Research results and conclusions expressed are those of the author and do not necessarily indicate concurrence by the Social Security Administration. The author wishes to thank Karen Smith of the Urban Institute and Thuy Ho of the Social Security Administration for their advice and data support. 


\section{Introduction}

Most recent evaluations of the Social Security Disability Insurance (DI) program have found that the intrinsic nature of disability insurance creates an incentive for work capable individuals to leave the labor force. While the research for older cohorts has consistently found low disincentive rates on the order of about 30 percent, recent studies on younger cohorts have suggested upper bound estimates of approximately 50 to 60 percent. ${ }^{1}$ Many of the rejected applicants do return to work, but it is clear from these numbers that there is still a substantial proportion of rejected DI applicants who do not return to work post application. Since most recommendations to reform the DI program would result in lower acceptance rates, it is important to understand the behavior of rejected workers. More stringent acceptance rates may decrease DI rolls but it may come at the expense of other social support programs as rejected DI applicants search for alternative sources of income replacement.

Evidence from recent evaluations of reforms to DI programs in other countries suggests that more stringent DI acceptance rates can result in increased dependency on other social support programs. For example, in the Dutch system, Borghans et al. (2011) find that a decrease in the generosity of DI benefits will have significant spillover effects onto other government programs such as unemployment insurance and general assistance. They estimate that for every euro saved on DI, the government has to spend an extra 51 cents on other social assistance programs. In the Austrian system, Staubli (2011) examined the effect of stricter eligibility criteria for disability insurance. He found that the stricter criteria decreased DI enrollment, but it also increased unemployment benefits by 3.5\% and sickness insurance benefits by $0.7 \%$.

In the U.S. context, there have been no policy reforms to exploit to answer this question, but we can glean some evidence from a study conducted by Bound et al. (2003) who examine the monthly income sources of DI applicants, using the 1990-1993 SIPP panels of data. When Bound et al. (2003) track these households three years before and after their DI filing date, they find that for rejected applicants there is no

\footnotetext{
${ }^{1}$ See Bound (1989) and Chen and van der Klaauw (2008) for estimates for older cohorts, and von Wachter (2011) for estimates for both cohorts.
} 
substantial change in the mean total monthly household income. The authors decompose household income by type (e.g., earnings, welfare income, spousal earnings, etc.), and find that the mean welfare participation rate of rejected applicants does not change post application. In an extension of their analysis, Bound and colleagues also follow a longitudinal sample of applicants, and provide estimates that show that there is substantial heterogeneity in changes in household income depending on where the household lies in the pre-application baseline household income distribution. Perhaps due to sample size limitation, the authors did not, however, provide quantile regression estimates by income source, so there are no results for public assistance income. Bound et al. (2003) note that one potential limitation of their study is the relatively short period of time that they are able to track households. They note that going back three years before the filing date may not adequately capture the full labor supply adjustments of the disabled worker. Burkhauser et al. (2001) have found using HRS data that 55\% of SSDI applicants experienced work-limiting health conditions more than three years before their filing date and 36\% experienced a work-limiting health condition more than10 years before.

In this study, I track the social support participation of male cohorts rejected from the disability program. A focus on social support outcomes is warranted given the need to understand the potential ramifications of an increase in stringency for the DI program. Importantly, filing cohorts are tracked from 10 years before to 10 years after first filing for DI. I show that by tracking cohorts from 10 years before, I am able to more accurately capture a baseline period before the onset of a work-limiting disability, and potential interactions between labor supply, social support participation and application to DI. As well, extending the follow-up period for up to 10 years after filing allows the worker to adjust to their denial. I construct the earnings history for each individual in the SIPP using administrative Detailed Earnings Records. The addition of this rich source of information provides a control for pre-application baseline earnings, a measure of labor force attachment. This is an important issue as there may be heterogeneous effects on social support program participation depending on where the household lies in the baseline earnings distribution. 
I use the 1990 to 2010 panels of the Survey of Income and Program Participation (SIPP) matched to administrative records made available by the Social Security Agency. These records include complete earnings and disability insurance application histories for all the subjects in the study sample. Using difference in difference models, I analyze how the social support participation of rejected DI applicants evolves from baseline to 10 years after the filing decision. I use two commonly employed control groups in the disability literature: healthy workers and DI beneficiaries. While the richness of the administrative data allows for a robust set of controls for pre-filing labor force attachment, it is still likely that rejected applicants differ in terms of health status. Therefore, the analysis provides two sets of parameters which are best viewed as upper bounds on the effect of being rejected from DI on social support participation. The first estimate answers the question: what is the average maximum change in social support participation that occurs when a worker who has applied to the DI program is rejected? The second estimate answers the question: what are the maximum average spillover effects from DI unto other social support programs?

I find persistent, positive effects of applying and being rejected from DI on social support participation. These effects are greatest for younger filing cohorts where they range in value from a maximum of $24.9 \%$ in the year of filing to $11.9 \% 10$ years after filing. For older cohorts the effects are lower but still persist. In terms of spillover effects, I find that rejected applicants are at least as likely, if not more so, to participate in social support programs as beneficiaries. Spillover effects are highest in the year after filing, approximately 3.6\%, but are statistically significant only for older cohorts.

This paper adds to the literature in several important ways. To start, this is the first paper to focus solely on rejected applicants, and to study the long term effects of being rejected from DI on social support participation in the U.S. Most literature on the DI program in the U.S. studies the disincentive effects of DI. In these papers the focus is predominantly on beneficiaries and on labor supply outcomes. As outlined earlier, one exception is the work of Bound et al. (2003), but their study covers only short-term effects (three years before and after filing) and they did not have the administrative data that I used in this study to control for lifetime earnings. Other similar studies to the present one, such as Borghans et al. (2011) and 
Staubli (2011) have used data from European countries. Though they exploit extremely rich administrative data, these countries have different institutions and social support systems, making it difficult to determine their relevance to the U.S. labor market. If we are to implement more stringent DI acceptance criteria, there will likely be spillovers onto other social support programs. By comparing the social support participation of DI rejected applicants with two control groups, I provide a benchmark for policymakers to use when trying to infer the effect of more stringent DI acceptance rates on other public social support programs in the U.S.

The rest of the paper is structured as follows: in the next section I provide a description of the data. This is followed in Section 3 by a description of the evaluation problem and the empirical strategies I will use to estimate treatment effects. In this section, I will explore the validity of the comparison group and discuss identification issues that arise when employing the selected control groups. In section 4, I present results from the different estimation methods. I also conduct additional analysis checks to see how sensitive the estimates are to labor force attachment and filing decade and discuss the implications of my findings. The final section concludes with a summary of the main results.

\section{Data}

The data assembled for this study consist of 1990 to 2008 panels of the Survey of Income and Program Participation (SIPP) merged with restricted Social Security administrative records. By themselves, the SIPP panels are rather short; most track individuals every month spanning time periods of between two to four years, depending on the panel. With the merged information from the administrative sources, the data now include the entire earnings histories from 1978 to 2010 for all individuals with covered earnings and the entire Social Security application and award history for applications fielded between 1988 and 2011. The inclusion of the earnings histories represents a marked advantage over most other datasets used to study the Social Security DI program because now the econometrician can control for earnings history and work experience with data that does not rely on self-reports. Likewise, the econometrician can also track the DI application history with the SSA administrative data. A detailed outline of the data sources 
used for this analysis is presented in Table 1.

To construct the dataset, the SIPP is first aggregated by calendar year. It is then merged with the earnings records and DI histories based on the SIPP ID and calendar year. With the merge, SIPP participants now have a filing date if they applied to the DI program. Non-applicants do not have a filing date, so for analysis purposes I randomly assign to these individuals a filing date between 1990 and 2010.

The main analysis sample consists of males, who are either applicants to the DI program or healthy workers, between the ages of 20 to 75 when we observe their program participation information in the SIPP. In addition, the only applicants in the sample were those that were between the ages of 30 to 65 when they first applied to the DI program. The sample includes both Title 2 (SSDI) and Title 16 (SSI) DI determinations. An applicant was considered rejected if they had not received DI within 10 years of their application. These are primary applicants (not reconsiderations or higher levels of adjudication). ${ }^{2}$ The sample selection criteria were the same as used in other studies on the DI program (von Wachter et al., 2011; Song, 2004). Applicants were only kept for filing years on or after 1990 and SIPP interview dates on or after 1989. Non-applicants were kept as a control group if their filing age was between 30-65 years based on their randomly assigned filing date. The resulting unbalanced panel dataset consists of 193,051 person year observations. ${ }^{3}$

The data are structured as an event analysis where the event, the first application to the DI program, occurs at $t=0$. The resulting dataset is unbalanced. Data for any of the time cohorts created (i.e. $t=-10$ to $t=10$ ) may consist of observations from any of the SIPP panels, and any calendar year. The fact that each time-event cohort is composed of multiple application year cohorts is an issue that I return to later. Each individual is then tracked across time in two-year intervals before or after the event. ${ }^{4}$ The sample is divided into three mutually exclusive groups. These are healthy workers, rejected DI applicants,

\footnotetext{
${ }^{2}$ The median time between filing and final decision is 130 days, the 25th and 75th percentile are approximately 70 and 281 days respectively.

${ }^{3}$ The frequencies of observations by time elapsed (lead or lag in years) between the date of the interview in the SIPP and the DI award decision from the SSA administrative data, along with further aspects of the data such as the number of observations from each SIPP panel, the number of observations by application year, and by date of interview from the SIPP, are relegated to the data appendix available upon request from the author.

${ }^{4}$ The data is aggregated to two-year intervals to ensure large enough sample sizes for statistical inference.
} 
and DI beneficiaries. People who report a work limiting or work preventing disability are not included in the analysis unless they are DI applicants. ${ }^{5}$ Summary statistics for the three groups are presented in Table 2; summary statistics are presented by whether the observation occurs in the years before or the years after the DI filing date. Presenting the data in this manner is a concise way to assess the comparability across groups. For young cohorts, men who apply to the DI program (Rejected and Accepted) are similar in terms of demographic characteristics. Compared to healthy workers applicants are more likely to be non-white, unmarried, and to have less than a high school diploma. All three groups are comparable in terms of age.

\section{Participation in social support programs}

The SIPP collects program participation data for each individual for each month of a SIPP panel. For the purposes of this study, I track participation in any of the following social support programs: Temporary Assistance to Needy Families (or its precursor, Aid to Families with Dependent Children); General Assistance; the Supplemental Nutrition Assistance Program (or its precursor, Food Stamps); and Unemployment Insurance. Participation in social support programs is coded " 1 ” if an individual participates in any of these programs throughout a calendar year and “0” otherwise. As shown in Table 2, applicants to the DI program (shown in the columns labeled “Accepted” and "Rejected”), have similar social support participation rates before and after DI filing. For healthy workers, participation rates remain the same before and after filing. Comparing younger cohorts in Schedule A to their older counterparts in Schedule B: participation rates are lower in general for the older filing cohort. Young rejected applicants have participation rate increases, post filing, as high as $27.5 \%$.

In order to more clearly highlight trends in participation, Figure 1 tracks social support program participation rates from 10 years before to 10 years after DI filing. The graphs are presented by filing age cohort where "Younger" is defined as filing for DI between the ages of 30 to 44 and "Older" if filing between the ages of 45-62. The graph on the left presents the data for the younger cohort. There one can see that there is no change in participation rate across the 21-year interval for younger healthy workers. For the

\footnotetext{
${ }^{5}$ Work limited/prevented observations could not be included as a control group because I do not have a complete work limiting disability record or history for the workers in my sample.
} 
+/- five years around the time of filing for DI, Figure 1 shows there is a peak in the social support participation in the year of filing. The peak tapers off approximately five years after rejection but results in a level shift upward in participation rates five to 10 years after filing. The program participation for the older cohort follows a similar pattern, but the post-filing level shift upward is much smaller. There is also a downward trend in social support participation for healthy workers.

The descriptive analysis in both Table 2 and Figure 1 suggests that filing for and being rejected from DI has a much larger permanent effect on social support program participation for younger cohorts than for older. We will explore this further in the multivariate analysis in the next section.

\section{Work Outcomes and Work History}

The administrative earnings data provided the information to construct current earnings, earnings history, and experience variables. Table 2 shows that mean current earnings are lower for applicants, and lower yet for rejected applicants, compared to healthy workers. A worker is considered to participate in the labor force if they have non-zero earnings. ${ }^{6}$ Mean participation rates pre-filing are above $83 \%$ for all groups. After filing, the labor force participation of rejected workers does rebound, but not completely, and earnings remain lower. Figure 2 shows a more explicit picture of the labor supply dynamics of the study samples across time. The graphs show that younger rejected applicants do go back to work, but neither their earnings nor their labor force participation rebound completely. Labor supply of rejected applicants is 23 percentage points lower in the final period $(t=10)$ than in the initial period $(t=-10)$. Earnings are $\$ 8,800$ less than their pre-filing level. Mean current earnings are lowest after the DI decision, and lower for older filing cohorts. For comparison purposes, similar labor supply outcomes were also plotted for healthy applicants. As is expected, for younger healthy cohorts participation rates do not change significantly across time but earnings do increase. For older cohorts, labor force participation and earnings decreases as healthy workers age into retirement. These life-cycle patterns are evident in Figure 2. They also mirror the patterns seen in similar recent studies, (see for example von Wachter et al., 2011), and are evident in Table 2.

\footnotetext{
${ }^{6}$ An alternative participation measure was generated based on the Federal minimum wage in a particular year, but given the larger amount of workers who earned less than this amount, I decided to use a less restrictive definition.
} 
To control for past earnings, I calculated the mean of the top eight of the 10 years before the filings decision. From Table 2 the mean past earnings follow the same patterns as current earnings. Healthy workers earn on average approximately $\$ 12,400$ more in the best eight out of 10 years prior to DI filing than rejected applicants. This difference remains after the DI decision as well.

Work experience is defined as the number of years between 1978 and the year we observe the individual in the SIPP when the individual earns more than the annual federal minimum wage. Because this variable is created using information from the Detailed Earnings Record it exists for all participants in the study even if we do not observe them during their application year in the SIPP. Table 2 shows the mean cumulative work experience is highest for healthy workers at approximately 9 years for the young sample and 17 years for the older sample. For applicants, the mean cumulative work experience is lower and similar in magnitude before and after the DI filing. These findings suggest that rejected DI applicants do not gain work experience post-filing. Similar trends are noted for the older cohort as well.

\section{Methods}

In this study, I use the social support dependency of rejected DI beneficiaries and healthy workers over a 21 year period to estimate the effect of DI rejection on public social support dependency. If an applicant is rejected from the DI program, it is likely that their dependency will go up (compared to pre-application years) if they are searching for alternative non-labor sources to maintain their household income and/or if they are unable to switch off of state-run welfare systems. By comparing rejected applicants with various control groups, I can estimate the effect of being rejected on public social support programs.

To implement this idea the treatment then is rejection from DI. The outcome of interest is social support program participation. The mean treatment effect is estimated using a difference in difference approach. $^{7}$ The first difference is over time where observations before the filing date are compared with those after the filing date. The second difference compares the rejected disability applicant treatment group

\footnotetext{
${ }^{7}$ The data available for this analysis are longitudinal, however, the sample is very unbalanced with very short panels. In order to exploit the time effects fully, it is best treated as repeated cross-sections.
} 
with an untreated control group of healthy workers so that:

$$
y=\beta_{0}+\beta_{1} G+\beta_{2} G T+X \beta_{3}+C \gamma+\varepsilon,
$$

where $y$ is social support participation, $G$ is an indicator variable for being in the treatment group (rejected from DI), and $T$ is an indicator equal to 1 if the observation came from the period on or after the year of filing. Importantly, $\beta_{2}$ denotes the mean treatment effect, that is, it provides an estimate of what the social support participation rate of the rejected worker would have been had they not applied to DI. The validity of this estimate rests on the assumption that we can control for the differences across groups. It is likely that rejected applicants differ from a control group of healthy workers by both their motivation for work and their health status. Observed earnings around the time of DI applications are affected by the interaction of applicants' self-selection behavior and the substantial gainful activity (SGA) requirement. Generally, these earnings are considered to be endogenous; thus, they contain no useful information. Fortunately, the richness of the administrative data allows for the construction of measures, such as prior work experience and earnings, to control for motivation and prior labor force attachment. These measures, along with demographic information such as age, marital status, education, and race, are included in the vector of control variables $X . C$ is a vector of calendar year dummies.

There is no reliable measure of health status available in the data for all time periods. The SIPP contains information on presence of a work-limiting or work-preventing disability. Among rejected workers, $45 \%$ report having a disability 9 to 10 years after filing compared to $12 \%$ at baseline. ${ }^{8}$ It is, therefore, likely that workers with no history of a disability are healthier than rejected applicants. If this is the case, then rejected applicants may not be able to return to the labor force after they are rejected, and therefore their social support dependency will be higher. ${ }^{9}$ Using treatment effects notation, the estimated counterfactual $E\left[y_{i}(0) \mid t_{i}=0\right]$ will be less than the true counterfactual $E\left[y_{i}(0) \mid t_{i}=1\right]$. The

\footnotetext{
${ }^{8}$ Unfortunately, the date of disability onset is missing, which prevented this measure of health status from being useful for this analysis. Furthermore, the administrative data only contained reliable date of disability onset information for DI beneficiaries.

${ }^{9}$ The upper bound interpretation will still apply if the rejected applicant remains out of the labor force to pursue further adjudications.
} 
estimate of the treatment effect is then best viewed as an upper bound on the true treatment effect, $\beta_{2}$.

It is clear from Figure 1 that the treatment effect $\beta_{2}$ is an average of the treatment effects across time. To fully exploit the panel nature of the dataset and estimate the treatment effect dynamics evident in social support participation, the group variable $G$ is interacted with an expanded set of time dummies, now represented by $T_{k}$, where $T_{k}=1$ if the observation comes from time period $k$ where $k \in[-10,10]$, i.e., $k$ ranges from 10 years before to 10 years after filing for DI. $G T$ in equation 1 is replaced with the interacted terms. The generalized version of 1 is then:

$$
y=\beta_{0}+\sum_{k=-9}^{10} \alpha_{1, k} T_{k}+\sum_{k=-10}^{10} \beta_{2, k} G T_{k}+X \beta_{3}+C \gamma+\varepsilon .
$$

In this case, $\beta_{2}$ is a vector of treatment effects with each element representing a time period. Treatment effects before the filing date provide estimates of any pre-filing adjustments that workers may go through. Likewise, the post-filing provides estimates of the time it takes the rejected worker to adjust to the DI filing decision.

As discussed earlier, estimation of an unbiased treatment effect using this approach relies on the underlying assumptions that the treatment and the control group are alike in terms of both observed and unobserved characteristics; and the control group accurately captures counterfactual trends in social support program participation in the absence of the treatment. A close inspection of Figure 1 suggests that the control group follows the same trajectory as the treatment group from five to 10 years before the event, and five to 10 years after the event. To further test this assertion, I estimate the social support participation rates from baseline to 10 years after filing using the following specification where a control group indicator, $U$, is also interacted with time to allow the program participation rate of the control group to change over time as well.

$$
y=\beta_{0}+\sum_{k=-9}^{10} \alpha_{1, k} U T_{k}+\sum_{k=-10}^{10} \beta_{2, k} G T_{k}+X \beta_{3}+C \gamma+\varepsilon .
$$


This specification was then used to test whether the trends in the treatment and control group are different at baseline (i.e., 8 to 10 years before filing). These estimates are presented in Figure 3.

An inspection of Figure 3 reveals no trend in program participation of the healthy worker-control group at baseline. This is confirmed by examining estimates of the $\alpha_{k}$ parameters as laid out in equation 2, and noting that they are all statistically insignificant and do not vary from baseline $(\mathrm{t}=-10)$. Moreover, the treatment group, between ( $t=-10$ and $t=-7$ ), does not exhibit a trend either. A Wald test of the null hypothesis that $\beta_{2,-10}=\beta_{2,-8}$ gives an $F$-statistic of $F(1,84829)=.012$ with a $p$-value $=0.912$ . Similarly, a Wald test performed at the end of the study period, where $\beta_{2,8}=\beta_{2,10}$, results in an estimated $F$-statistic of $F(1,84829)=.002$ with a $p$-value $=0.965$. Similar tests were performed for the older cohort sample and in all cases the null hypothesis cannot be rejected. While this is the first study to examine social support outcomes, other studies using earnings and labor force participation have gone as far back as 10 years, and have shown there is no interaction yet with the DI application (Giertz and Kubik, 2011; von Wachter et al., 2011; Song, 2004).). Song (2004), in his study of the earnings of DI applicants, contends that "pre-disability earnings appear to be the most suitable because they are ... determined years before the earliest application. Unlike earnings during the post-application period, pre-disability earnings can be considered to be exogenous with respect to DI application incidence.” I make the same assertion for social support participation -- by going back far enough, social support participation becomes exogenous, and both the treatment and the control group follow the same trajectory at baseline.

\section{Results}

The earlier descriptive analysis suggested clear post-filing differences in social support program participation of applicants rejected from the DI program. In this section, I present estimates for the difference in difference models outlined in equations 1 and 2. Table 3 reports estimates for the baseline model laid out in equation 1 . The first column reports estimates with no controls, and column two reports estimates for the model that controls for demographics, prior earnings, current earnings, work experience, 
and calendar year dummies. The estimates are presented by filing age cohort. Schedule A shows that the mean effect of being rejected from the DI program for younger cohorts is approximately $11 \%$ but decreases to $10 \%$ when controls are included in the second column. The effects for the older cohort are much smaller, and are approximately $4 \%$ for both specifications.

The estimates for the more general model outlined in equation 2 are presented in Figure 4 for the younger and older cohorts. The parameters are precisely estimated from 6 years before the filing date to the end of the study period for the younger cohort and for all periods for the older. In all of these time periods, the magnitudes of the parameter estimates are greatest for the younger cohort. Peak estimates for both cohorts occur during the file year $t=0$ and they are, at most, approximately $25 \%$ and $19.5 \%$, respectively. For both cohorts, the estimates decline post filing but still remain higher than at baseline, so that 10 years after filing for DI the estimated mean effect of being rejected on social support participation for each cohort is at most $12 \%$ and $7 \%$ respectively. These estimates suggest that there are long-term effects on other social support programs of applying and being rejected from the DI program.

\section{Effects by pre-filing labor force attachment}

To explore how the estimates differ by pre-filing labor force attachment, each sample is partitioned into two groups: those that make above the median income and those that make below, based on their mean pre-filing earnings. Median prior earnings for younger workers is approximately $\$ 20,797$ and for the older filing cohort it is $\$ 28,223$. Equation 1 is then estimated for these subsamples and the parameter estimates are reported in Table 4, columns two and three. For younger workers with lower labor force attachment, the treatment effect estimates are 9.7\%. For younger workers with higher labor force attachment, the treatment estimates are 1.2 percentage points lower. For the older filing cohorts, the sample with lower labor force attachment has a treatment effect of $6.6 \%$. The effect for higher labor force attachment and older workers is insignificant. Figure 5 plots estimates for the more general model outlined in equation eq:eq2. ${ }^{10}$ For younger and older cohorts with low labor force attachment, the mean treatment effects are similar up to and

\footnotetext{
${ }^{10}$ Only the estimates for lowest labor force attachment groups are presented here. The estimates for the higher labor force attachment group followed a similar pattern but were lower in magnitude and insignificant in most cases.
} 
including the year of filing -- approximately 23-24\%. After filing, younger cohorts have higher treatment effects between 6 to 10 years after filing. At 10 years post-filing the treatment effect estimates are the same at $10 \%$ for the younger and older cohorts.

\section{Effects by Filing Decade}

As discussed earlier, the event data mixes together individuals from multiple calendar years into duration cohorts before, during, and after filing for DI. These “mixed” calendar year samples provide a way to infer the mean change in a worker's program participation as long as each cohort is considered to be a random sample of the same population. If, for example, filers in the 2000s have higher baseline income than those in the 1990s, then this assumption would not hold unless controls were included for previous earnings history and labor force attachment. In the present analysis, I control for both. As noted earlier, these histories start at 10 years before filing for mean earnings, and go back to 1979 for experience variables. In addition, I include calendar year explicitly in equations 1 and 2 to take into account economic conditions.

Nevertheless, there may be other changes in the underlying distribution of each filing cohort. For example, there may be a change in the underlying health distribution of rejected applicants towards better health. While I do not have the data to follow each filing year individually, I separate the data into filers in the 1990s and those in the 2000s. I then determine how sensitive the treatment effect estimates are between cohorts of individuals who filed in the 1990s and those who filed in the 2000s. Results by filing decade are presented in Table 4, columns (4)-(5). They show higher treatment effects for filers in the 2000s compared to the 1990s. The mean average effect of being rejected was $13.8 \%$ for filers between $2000-2011$ and $4 \%$ in the 1990s. For older cohorts, the numbers were smaller at 1.5 and 5.2\% respectively. Figure 6 plots the parameter estimates for the more general model. The estimates for all samples are either similar or higher in the 2000s. For older cohorts, the mean rates of participation are similar. For younger cohorts, post filing, the treatment effects are larger by $6 \%$ percentage points in the 2000 s than in the 1990 s $(27.7 \%$ compared to 21.6\%). Ten years after filing, the rates of participation are very high for both cohorts in the 2000s. Controls were added in the models to pick up year effects (i.e., the Great recession), but even so, these differences remain. 


\section{Spillover Effect Estimates}

The above estimates use healthy workers as a control group for rejected disability applicants. If DI beneficiaries are used instead, the treatment effects identified can then be interpreted as spillover effects. Spillover effects are relevant because they tell us whether rejected applicants turn to other social support programs when they are rejected from DI.

The estimated spillover effects are reported in Table 5. Without controls, the effect is $10.9 \%$. When controls are included, the effect is $7.1 \%$ for the younger cohort (see columns one and two), and lower at 2.9\% for the older cohort. Estimates for the more generalized model of equation 2 are presented in Figure 7. The results reported in Figure 7 show that treatment effects are small and mostly insignificant, except for in the two years after filing for the older cohort, where the effects is $3.5 \%$. In the long term there is no significant difference in participation rates.

Figure 1 shows that the welfare participation of beneficiaries is equal to or lower than that of rejected applicants in most time periods for older cohorts, and in the time periods around the time of application $t=[-4,+4]$. If this is the case, then the desired counterfactual is actually greater than the observed behavior of beneficiaries: $E\left[y_{i}(0) \mid t_{i}=0\right] \geq E\left[y_{i}(0) \mid t_{i}=1\right]$. Since beneficiaries get a disability payment, they would be less dependent on social support programs than their rejected counterparts post-filing. The estimates provided here would then represent upper bounds on the spillover effects of rejection from DI into other government programs.

Columns (3)-(6) of Table 5 provide estimates by labor force attachment and by decade. Spillover effects are more pronounced in 2000-2013 than they are in the 1990s as seen in columns four and five. For older filers the spillover effects are approximately $2.9 \%$ and largely concentrated among workers with low labor force attachment (see columns three and four). For younger workers the patterns are not as clear. Young workers with higher attachment have greater mean social support participation post filing at 10.7\% compared to $6.6 \%$ for lower attached workers. 


\section{Discussion}

A worker is rejected from the DI program if, based on their medical condition and education or vocational experience, they are deemed to be capable of substantial gainful activity and work. Since many rejected applicants do not return to the labor force, this paper examines whether they use other social support programs to fund their consumption. The results presented here suggest that they are more likely to participate in federal social support programs than healthy workers. Moreover, the longitudinal estimates show that as the rejected workers approach the filing date, the treatment effects start to increase and reach a maximum in the year of filing, where rejected workers are on average $25 \%$ more likely to depend on social support programs than healthy workers. The effects then dissipate slowly so that at 10 years after they are still on average $12 \%$ more likely to depend on social support programs than healthy workers. The longitudinal estimates also show that the treatment effects are concentrated among workers who file at a younger age and who have lower labor force attachment.

There have been no substantive changes in the disability awards process since 1984, but Autor and Duggan (2006), and more recently von Wachter et al. (2011), have suggested that there has been an increase in the number of applicants who apply to DI for economic rather than health motivations. ${ }^{11}$ von Wachter et al. (2011) finds, in his study of cohorts of applications in the 1990s and early 2000s, that workers in more recent filing years are more likely to apply to the DI program because of economic circumstances. If this is the case, then the underlying health distribution of rejected applicants would move towards better health, and more recent cohorts should have increased capacity for substantial gainful activity and decreased social support dependency. The estimates reported above by decade of application do not support the conjecture of decreased social support dependency. Younger filers had much higher treatment effects in the 2000s than they did in the 1990s. In the 2000s younger workers were 13\% more likely to participate in social support programs than healthy workers. Contrast this result with $4 \%$ in the 1990 s.

\footnotetext{
${ }^{11}$ There were some smaller internal changes such as: increased public awareness campaigns designed to help potentially eligible individuals apply for benefits (in the early 1990s) and changes in the issuance for musculoskeletal listings and obesity that took place in the 1990s, however, these changes did not contribute meaningfully to increases in applications (SSA, 2006).
} 
A further complication in the analysis of social support behavior of DI applicants is the potential interaction between the DI program and state-run welfare programs such as Temporary Assistance to Needy Families (TANF) and Medicaid. Wiseman (2011) and Burkhauser and Daly (2011) note that welfare programs such as Temporary Assistance to Needy Families (TANF), are administered at the state level and financed through block grants. As a result, states may attempt to lighten their welfare caseloads by encouraging recipients to apply to federally funded programs such as DI. ${ }^{12}$ If this is indeed a motivating factor in DI application, then an increase in the stringency of acceptance rates will hypothetically result in rejected DI applicants having higher welfare participation post-application. While my analysis does not provide specific estimates of this type of shifting behavior by states, it does provide evidence of whether the patterns in the data are consistent with welfare shifting.

If welfare shifting is occurring, we should observe three patterns in the data. First, there should be an increase in the social support dependency of rejected workers relative to healthy workers -- we observe this. Second, we should see similar social support participation patterns between rejected applicants and beneficiaries before filing and then a divergence, as beneficiaries transition onto DI and away from other social support programs -- we observe this in our spillover effect estimates, albeit for only one time period following filing. That is, when the control group in the above analyses was changed to beneficiaries, the spillover effects from DI were estimated to be, at most, 4.3\%. These spillover estimates varied across time with the largest magnitudes occurring in the first two years after filing, where rejected applicants were 3.6\% more likely to participate in social support programs. In all subsequent periods the results were not significant.

Finally, if welfare shifting is occurring, we should also notice that the spillover estimates by decade are higher in the 2000s, when welfare reform had already taken effect, than in the 1990s. This finding is also observed in the estimates, (at most 9.4\% versus 3.4\% in the 1990s). While these findings lend support to

\footnotetext{
${ }^{12}$ The DI program consists of the Supplemental Security Income (SSI) program and the Social Security Disability Insurance (SSDI) program. Both parts of the program require that the worker have a work preventing disability but the SSDI part of the program requires that you have at least 40 quarters of covered earnings while for the SSI program there is also an income criterion. For SSI you do not have to have covered earnings. Both Wiseman (2011) and Burkhauser and Daly (2011) focus on the SSI part of the program in their discussion.
} 
and Wiseman's and Burkhauser and Daly's conjectures, they are by no means a conclusive test of welfare shifting. Further analysis by state, with more well defined time periods before and after the introduction of welfare reform, would need to be conducted to confirm their conjecture. Unfortunately, these data do not include geographical identifiers to allow this type of analysis and the sample sizes of rejected beneficiaries are not large enough to allow for shorter application periods than a decade. ${ }^{13}$

\section{Conclusion}

One of the alternatives available to policymakers contemplating restructuring the DI program, with an aim of decreasing DI caseloads, is to adjust the program rules by strengthening disability criteria. Doing so would both deter people from applying and reject more applicants. The extant literature lends support to tightening eligibility criteria because of its focus on labor supply behavior and the finding that a substantial portion of younger rejected workers return to work. Even so, there are still a significant proportion of individuals in both younger and older cohorts who do not return to work and who do not return to their pre-filing earnings levels. In this paper, I explore potential ways to answer the question of how/whether more stringent DI eligibility criteria will affect dependency on other Federal/State social support programs. Obtaining credible estimates, or even reliable bounds on these estimates, is difficult in a setting such as the U.S. where there have been no policy changes that would allow researchers to exploit a natural experiment. In light of these circumstances, this paper examined whether rejected applicants are more likely to depend on social support programs post-DI filing compared to two reference groups: a group of healthy workers and a group of DI beneficiaries. In the first analysis, the treatment effect identified is the mean effect of applying and being rejected from DI. I present both an average estimate of the difference in social support participation and I show how this average is distributed over time with the treatment effects being largest around the time of filing. I also show that the effects of applying and being rejected from the DI program are permanent. Ten years after filing, rejected applicants are on average 13\% more likely to participate in social

\footnotetext{
${ }^{13}$ The younger and older filing cohort samples were divided into application cohorts: 1990-1995, 1996-2000, 2001-2006, 2007-2011. The sample of rejected applicants in each of these application cohorts was too small to conduct longitudinal analysis.
} 
support programs than healthy workers. Larger effects are found for sub-groups of workers with lower labor force attachment or who were rejected from DI between 2000-2013. This study also estimates spillover effects of at most 7\%. That is, rejected DI applicants are at most 7\% more likely than beneficiaries to depend on social support programs.

More stringent DI eligibility rules have two effects: they reject more people in the pipeline, and they discourage people from applying. For those applicants already in the DI application pipeline, if more stringent eligibility criteria result in more rejected applicants, then the spillover effect on other social support programs is likely to be even larger than the upper bound estimates presented here. Under the existing program rules, I have estimated upper bound spillover effects of 7\%. With new tighter eligibility criteria, these spillover effects are likely to be higher if rejecting more people changes the underlying health distribution of rejected applicants so that on average they are unhealthier. If, on the other hand, tightening the eligibility criteria discourages people from applying altogether, then the estimates suggest that if rejected applicants did not apply there would be at most a 12\% decrease in the social support participation of this population.

Taken together, the findings of this paper suggest that policies that tighten eligibility criteria -- and increase the number of rejected applicants -- have the potential to impact other social support programs. This study shows that even for workers who are rejected, the act of applying seems to make them more likely to participate in social support programs. Policies that provide incentives to employers to intervene early and strengthen incentives for people with disabilities to continue to work would be one type of intervention that could be considered. 


\section{References}

Autor, D. H. and M. G. Duggan (2006). The growth in the social security disability rolls: A fiscal crisis unfolding. The Journal of Economic Perspectives 20(3), 71-96.

Borghans, L., A. Gielen, and E. Luttmer (2011). Social support shopping: Evidence from a regression discontinuity in disability insurance reform. IZA Paper No. 5412.

Bound, J. (1989). The health and earnings of rejected disability insurance applicants. American Economic Review 81, 1427-1434.

Bound, J., R. V. Burkhauser, and A. Nichols (2003). Tracking the household income of SSDI and SSI applicants. Research in Labor Economics 22, 113-158.

Burkhauser, R., J. Butler, and R. Weathers (2001). How policy variables influence the timing of applications for social security disability insurance. Soc. Sec. Bull. 64(52).

Burkhauser, R. V. and M. Daly (2011). The Declining Work and Welfare of People with Disabilities: What Went Wrong and a Strategy for Change. AEI Press.

Chen, S. and W. van der Klaauw (2008). The effect of disability insurance on labor supply of older individuals in the 1990s. Journal of Econometrics 142(2), 757-784.

Giertz, S. H. and J. D. Kubik (2011). The disability screening process and the labor market behavior of accepted and rejected applicants: Evidence from the health and retirement study. Journal of Labor Research 32(3), 237-253.

Song, J. G. (2004). Using predisability earnings as an instrument for disability determination outcomes. Social Security Administration, Office of Policy, Office of Research, Evaluation, and Statistics (104).

SSA (2006). Trends in the Social Security and Supplemental Security Income Disability Programs. Technical Report, Social Security Administration Publication No. 13-11831.

Staubli, S. (2011). The impact of stricter criteria for disability insurance on labor force participation. Journal of Public Economics 95(9), 1223-1235.

Von Wachter, T., J. Song, and J. Manchester (2011). Trends in employment and earnings of allowed and rejected applicants to the Social Security Disability Insurance program. American Economic Review 101(7), 3308.

Wiseman, M. (2011). Supplemental security income for the second decade. Poverty \& Public Policy 3(1), 1-18. 


\section{Tables and Figures}

Table 1: Data Sources

\begin{tabular}{|c|c|c|c|}
\hline Dataset & Years & Data Source & Data Notes \\
\hline SIPP & $1990-2008$ & Public Use & $\begin{array}{l}\text { Demographic, program } \\
\text { participation and disability } \\
\text { information. }\end{array}$ \\
\hline Detailed Earnings Record ${ }^{\mathrm{a}}$ & $1978-2010$ & Confidential & Earnings histories. \\
\hline Supplemental Earnings Record ${ }^{\mathrm{a}}$ & $1978-2010$ & Confidential & Earnings histories. \\
\hline Supplemental Security ${ }^{\mathrm{a}}$ & $1980-2011$ & Confidential & $\begin{array}{l}\text { Updated DI adjudications above } \\
\text { the state level. }\end{array}$ \\
\hline Master Beneficiary Record ${ }^{\mathrm{a}}$ & $1980-2011$ & Confidential & $\begin{array}{l}\text { Updated DI adjudications above } \\
\text { the state level. }\end{array}$ \\
\hline 831 file: Disability Applications ${ }^{\mathrm{a}}$ & $1988-2011$ & Confidential & DI application \\
\hline
\end{tabular}

${ }^{\mathrm{a}}$ The administrative data were procured when the author was a Special Sworn Status researcher at the Social Security Agency. 
Table 2: Means

\section{A. Younger Cohort}

Married

Nonwhite

More than HS

Age

Labor Force Participation

Current Earnings, 1,000s

Previous Earnings, 1000s ${ }^{1}$

Cumulative Experience

Social Support Participation

No. of observations

$\begin{array}{rr}\text { Healthy } & \text { Accepted } \\ 63.1 & 46.3 \\ 13.2 & 18.6 \\ 60.4 & 36.2 \\ 32 & 33 \\ 94.7 & 87.5 \\ 21.1 & 11.8 \\ 22.7 & 13.0 \\ 9 & 8 \\ 7.4 & 17.1 \\ 39589 & 2949\end{array}$

Before

$R$

Healthy
74.4
14.3
65.3
41
94.8
28.7
21.7
16
6.7
40248

After

Accepted

48.6

24.7

38.3

42

33.2

2.4

11.1

9

26.6

3406

Rejected

49.9

27.6

40.8

41

61.5

5.7

9.4

9

27.5

2247

\section{B. Older Cohort}

\section{Married}

Nonwhite

More than HS

Age

Labor Force Participation 1

Current Earnings, 1000s ${ }^{1}$

Previous Earnings, 1000s ${ }^{1}$

Cumulative Experience

Social Support Participation

No. of observations

$\begin{array}{rrrrrr}79.5 & 70.6 & 67.2 & 80.7 & 64.8 & 65.2 \\ 11.5 & 19.0 & 23.0 & 12.8 & 21.2 & 24.1 \\ 63.1 & 38.6 & 42.9 & 63.8 & 38.1 & 40.0 \\ 48 & 51 & 49 & 58 & 59 & 58 \\ 93.4 & 89.6 & 82.9 & 81.1 & 26.7 & 41.0 \\ 30.5 & 17.2 & 12.9 & 26.3 & 1.9 & 3.6 \\ 32.9 & 19.2 & 14.9 & 31.5 & 17.0 & 15.2 \\ 17 & 15 & 14 & 21 & 15 & 14 \\ 5.8 & 12.3 & 14.5 & 4.6 & 16.0 & 18.9 \\ 40064 & 10867 & 4292 & 34270 & 8747 & 3587 \\ \text { rorce participation is an indicator for earnings greater than zero. Cumulative } \\ \text { rom 1978 to the present. All earnings are reported in real terms with }\end{array}$


Table 3: Treatment Effects Estimates ${ }^{1}$

\begin{tabular}{lcc}
\hline A. Younger Filing Cohort & $\mathbf{1}$ & $\mathbf{2}$ \\
\hline$\beta_{1}$ & 9.5 & 6.4 \\
& $(0.9)$ & $(0.9)$ \\
$\beta_{2}$ & 10.9 & 9.7 \\
& $(1.6)$ & $(1.6)$ \\
Controls & & $\mathrm{X}$ \\
& & \\
No. of observations & 84,869 & 84,869 \\
& & \\
B. Older Filing Cohort & & 7.0 \\
\hline$\beta_{1}$ & 9.3 & $(0.7)$ \\
$\beta_{2}$ & $(0.8)$ & 4.2 \\
& 4.3 & $(1.2)$ \\
Controls & $(1.2)$ & $\mathrm{X}$ \\
No. of observations & 82,213 & 82,213 \\
\hline
\end{tabular}

${ }^{1}$ This table provides estimates of the treatment effects in equation 1. Column (2) includes controls for marital status, race, education, a quadratic in age, current earnings, previous earnings, cumulative work experience, and calendar year indicators. The younger cohort is 30 to 44 years of age at DI filing. The older cohort is 45 to 62 at DI filing. Standard errors (in parentheses) are adjusted for clustering on person identifiers. 
Table 4: Sensitivity Analysis I: Treatment Effect Estimates ${ }^{1}$

\begin{tabular}{|c|c|c|c|c|c|}
\hline & & $\begin{array}{r}\text { Prior } \\
\text { A } \\
\end{array}$ & $\begin{array}{l}\text { Force } \\
\text { ent }\end{array}$ & Applic & Decade \\
\hline & & Low & High & 1990s & $2000 \mathrm{~s}$ \\
\hline $\begin{array}{l}\text { A. Younger } \\
\text { Filing Cohort }\end{array}$ & 1 & 2 & 3 & 4 & 5 \\
\hline$\beta_{1}$ & $\begin{array}{c}6.4 \\
(0.9)\end{array}$ & $\begin{array}{c}6.0 \\
(1.8)\end{array}$ & $\begin{array}{c}2.8 \\
(1.6)\end{array}$ & $\begin{array}{c}9.6 \\
(1.9)\end{array}$ & $\begin{array}{c}5.4 \\
(1.0)\end{array}$ \\
\hline$\beta_{2}$ & $\begin{array}{c}9.7 \\
(1.6)\end{array}$ & $\begin{array}{c}9.7 \\
(1.8)\end{array}$ & $\begin{array}{c}8.5 \\
(3.2)\end{array}$ & $\begin{array}{c}4.0 \\
(2.5)\end{array}$ & $\begin{array}{l}13.8 \\
(2.3)\end{array}$ \\
\hline $\begin{array}{l}\text { Controls } \\
\text { No. of } \\
\text { observations }\end{array}$ & $\begin{array}{c}X \\
84,869\end{array}$ & $\begin{array}{c}X \\
40,518\end{array}$ & $\begin{array}{c}X \\
44,351\end{array}$ & 41,728 & 43,141 \\
\hline $\begin{array}{l}\text { B. Older Filing } \\
\text { Cohort }\end{array}$ & & & & & \\
\hline$\beta_{1}$ & $\begin{array}{c}7.0 \\
(0.7)\end{array}$ & $\begin{array}{c}7.1 \\
(0.9)\end{array}$ & $\begin{array}{c}3.3 \\
(1.1)\end{array}$ & $\begin{array}{c}8.6 \\
(1.6)\end{array}$ & $\begin{array}{c}6.6 \\
(0.8)\end{array}$ \\
\hline$\beta_{2}$ & $\begin{array}{c}4.2 \\
(1.2)\end{array}$ & $\begin{array}{c}6.6 \\
(1.5)\end{array}$ & $\begin{array}{l}-1.1 \\
(1.4)\end{array}$ & $\begin{array}{c}1.8 \\
(2.0)\end{array}$ & $\begin{array}{c}5.2 \\
(1.5)\end{array}$ \\
\hline Controls & $\mathrm{X}$ & $\mathrm{X}$ & $\mathrm{X}$ & $X$ & $X$ \\
\hline $\begin{array}{l}\text { No. of } \\
\text { observations }\end{array}$ & 82,213 & 37,260 & 44,953 & 33,445 & 48,768 \\
\hline
\end{tabular}

${ }^{1}$ All specifications include controls for marital status, race, education, a quadratic in age, current earnings, previous earnings, cumulative work experience, and calendar year indicators. Column (1) repeats the treatment effects from the previous table for comparison purposes. Columns (2) -- (3) report estimates by pre-filing labor force attachment. The low attachment sample has mean pre-filing earnings below the median and the high attachment is above the median of mean pre-filing earnings. Columns (4) -- (5) report estimates by decade of filing: the 1990s and 2000-2011. Standard errors (in parentheses) are adjusted for clustering on person identifiers. 
Table 5: Sensitivity Analysis II: Spillover Effect Estimates ${ }^{1}$

\section{A. Younger Filing Cohort}

$\beta_{1}$

$\beta_{2}$

Controls

No. of observations

\section{B. Older Filing Cohort}

$\beta_{1}$

$\beta_{2}$

Controls

No. of observations

1

$-5.67$

10.94

11,387

0.58

(0.84)

4.31

(1.20)
(2)-(2) report the baseline treatment effect without and with controls and calendar year indicators. Columns (3) -- (4) report estimates by pre-filing labor force attachment. The low attachment sample has mean pre-filing earnings below the median and the high attachment is above the median of mean pre-filing earnings. Columns (5) -- (6) report estimates by decade of filing: the 1990s or 2000-2011. Standard errors (in parentheses) are adjusted for clustering on person identifiers.

\section{Prior Labor Force}

Attachment

\section{Application Decade}

$\begin{array}{cccc}\text { Low } & \text { High } & 1990 \mathrm{~s} & 2000 \mathrm{~s} \\ \mathbf{3} & \mathbf{4} & \mathbf{5} & \mathbf{6} \\ -4.08 & -0.84 & -1.28 & -5.25 \\ (1.48) & (1.97) & (2.28) & (1.56) \\ 6.57 & 10.73 & 3.36 & 9.35 \\ (1.98) & (3.30) & (2.80) & (2.63) \\ \mathrm{X} & \mathrm{X} & \mathrm{X} & \mathrm{X} \\ 9,251 & 2,136 & 5,529 & 5,858\end{array}$

$-0.28-0.88$

(1.16)

$-0.33$

$-1.37$

0.66

(0.85)

(1.08)

3.75

(1.76)

(0.98)

(1.52)

(1.21)

(1.49)

3.79

1.56

(1.61)

$\mathrm{X}$

$\begin{array}{ccc}X & X & X \\ 7,851 & 11,158 & 16,335\end{array}$

.



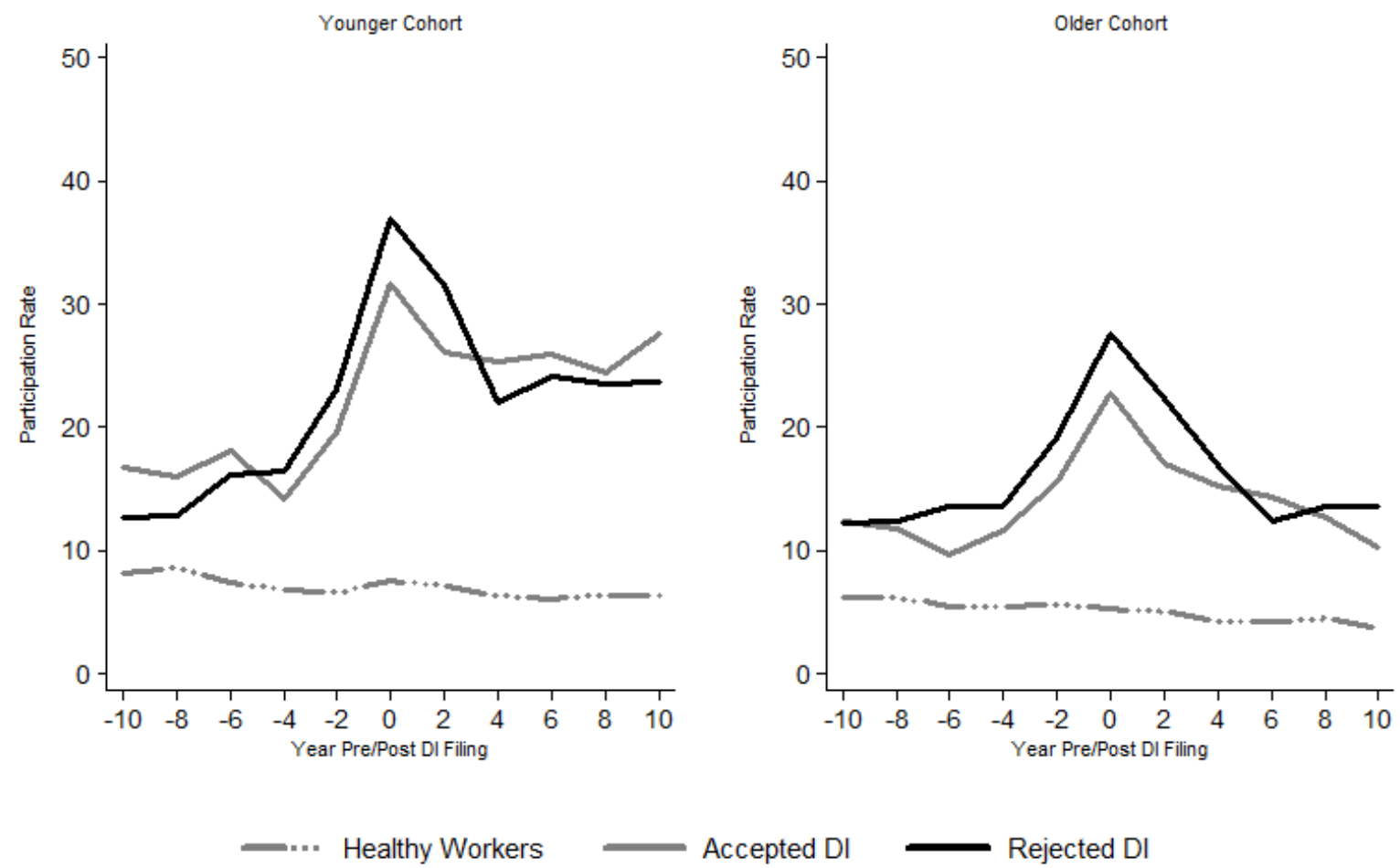

Note: Younger Cohort: age 30-44 at filing; Older Cohort: age 45-62 at filing.

Figure 1: Social Support Participation 

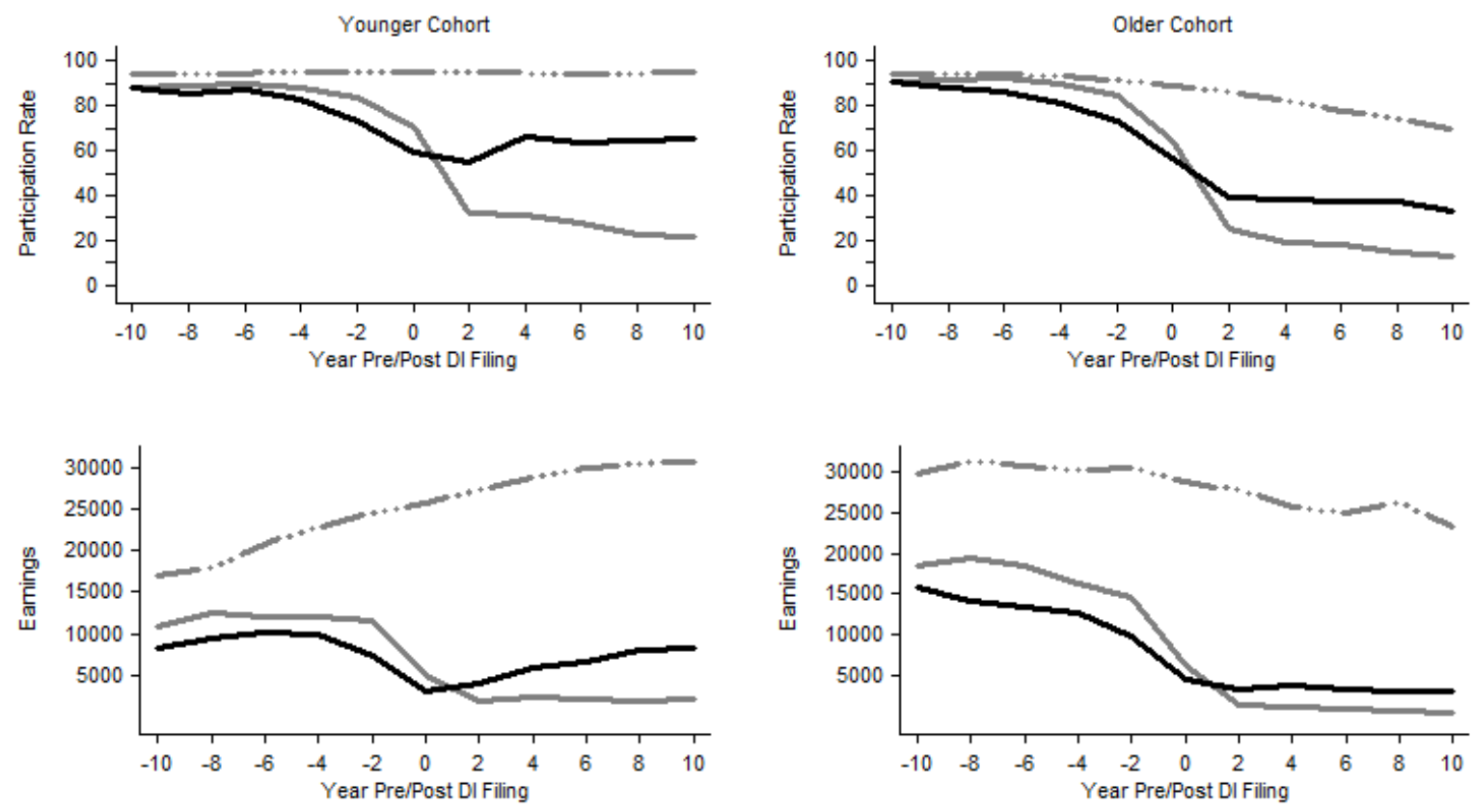

L.." Healthy Workers

Accepted DI

Rejected DI

Note: Younger Cohort: age 30-44 at filing; Older Cohort: age 45-62 at filing.

Figure 2: Labor Force Participation and Earnings 

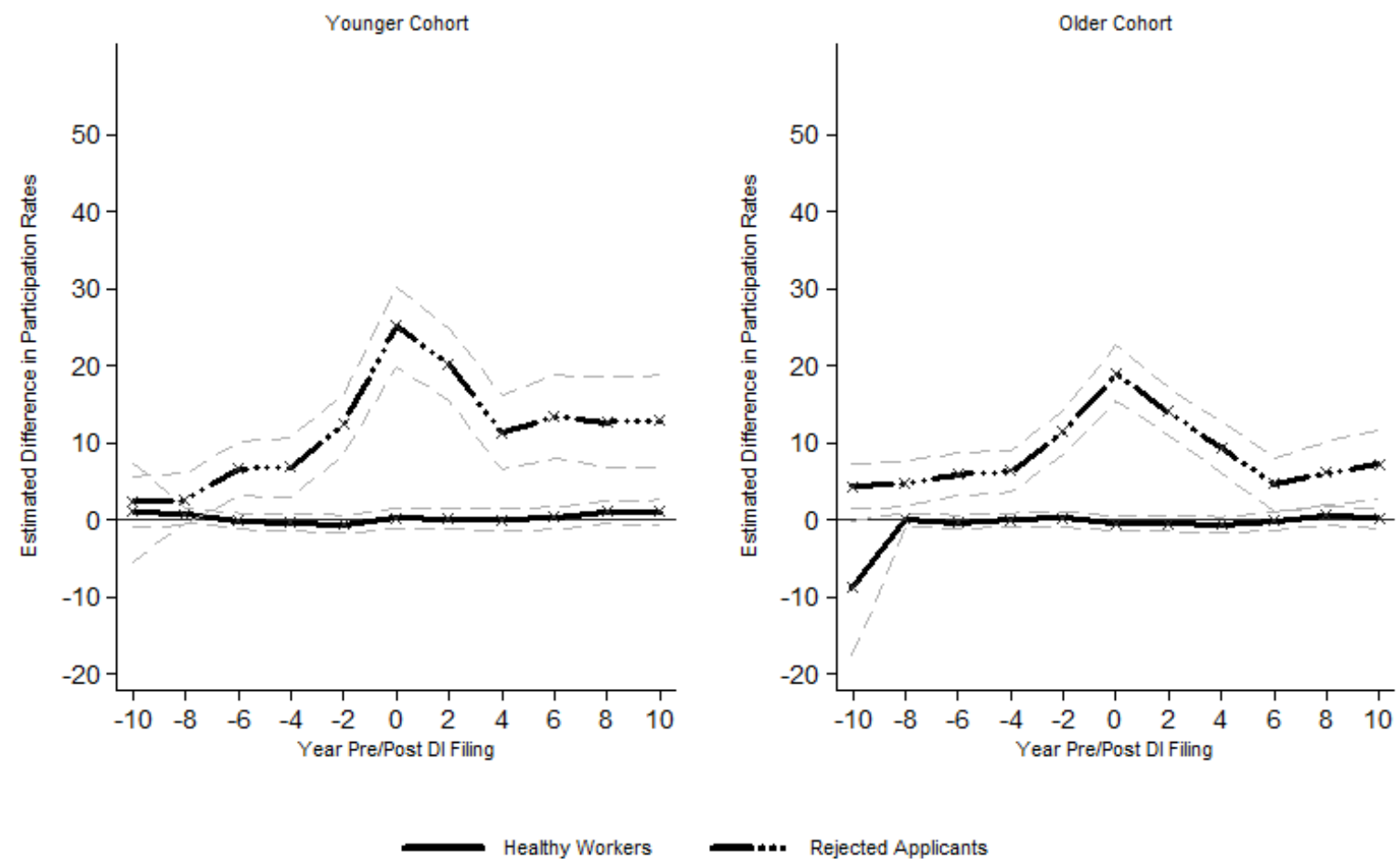

Note: The grey hatched lines represent the 95-percent confidence interval.

Figure 3: Estimated Change in Social Support Participation Rate By Comparison Group 


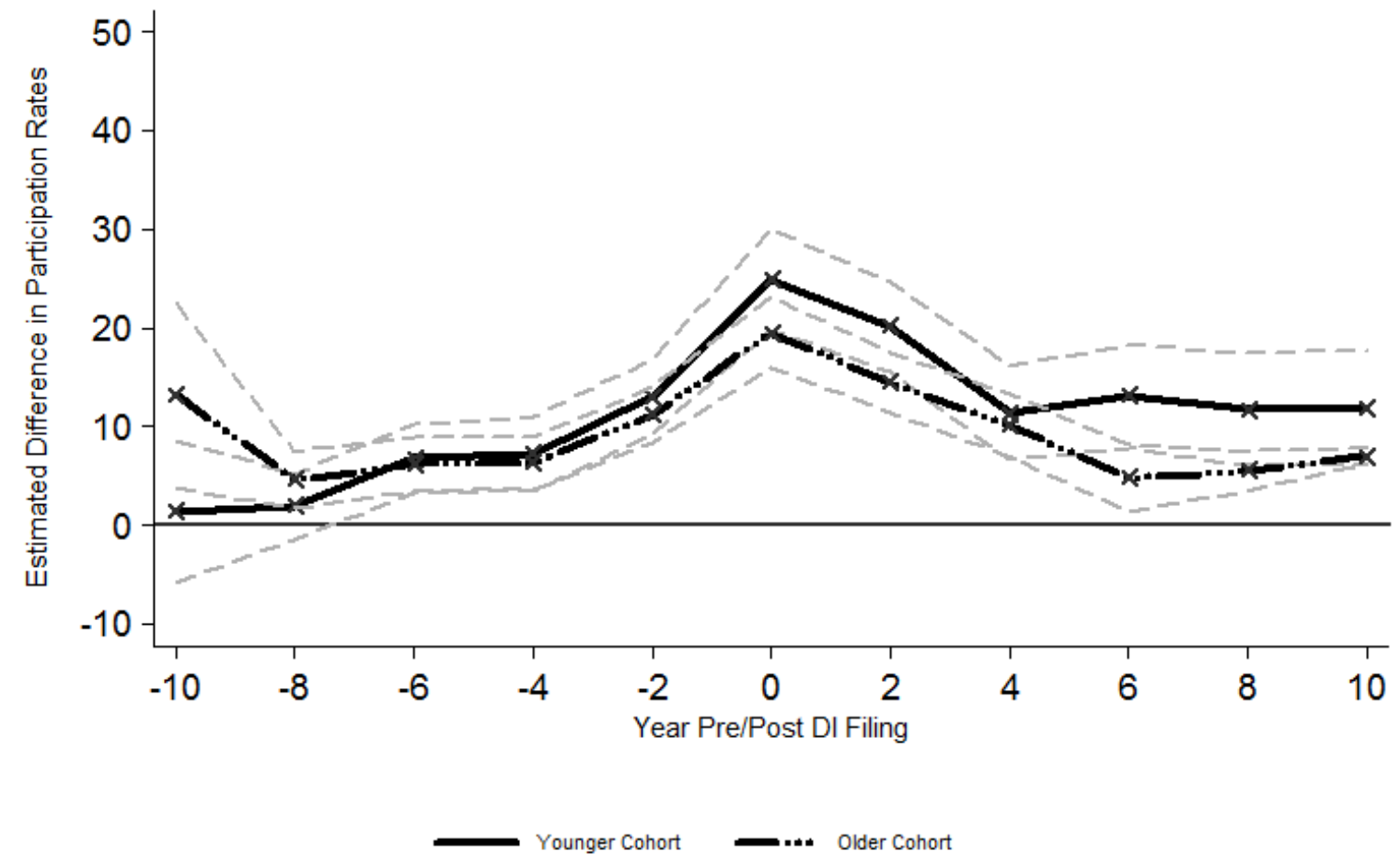

Note: The grey hatched lines represent the 95-percent confidence interval.

Figure 4: Estimated Treatment Effects 


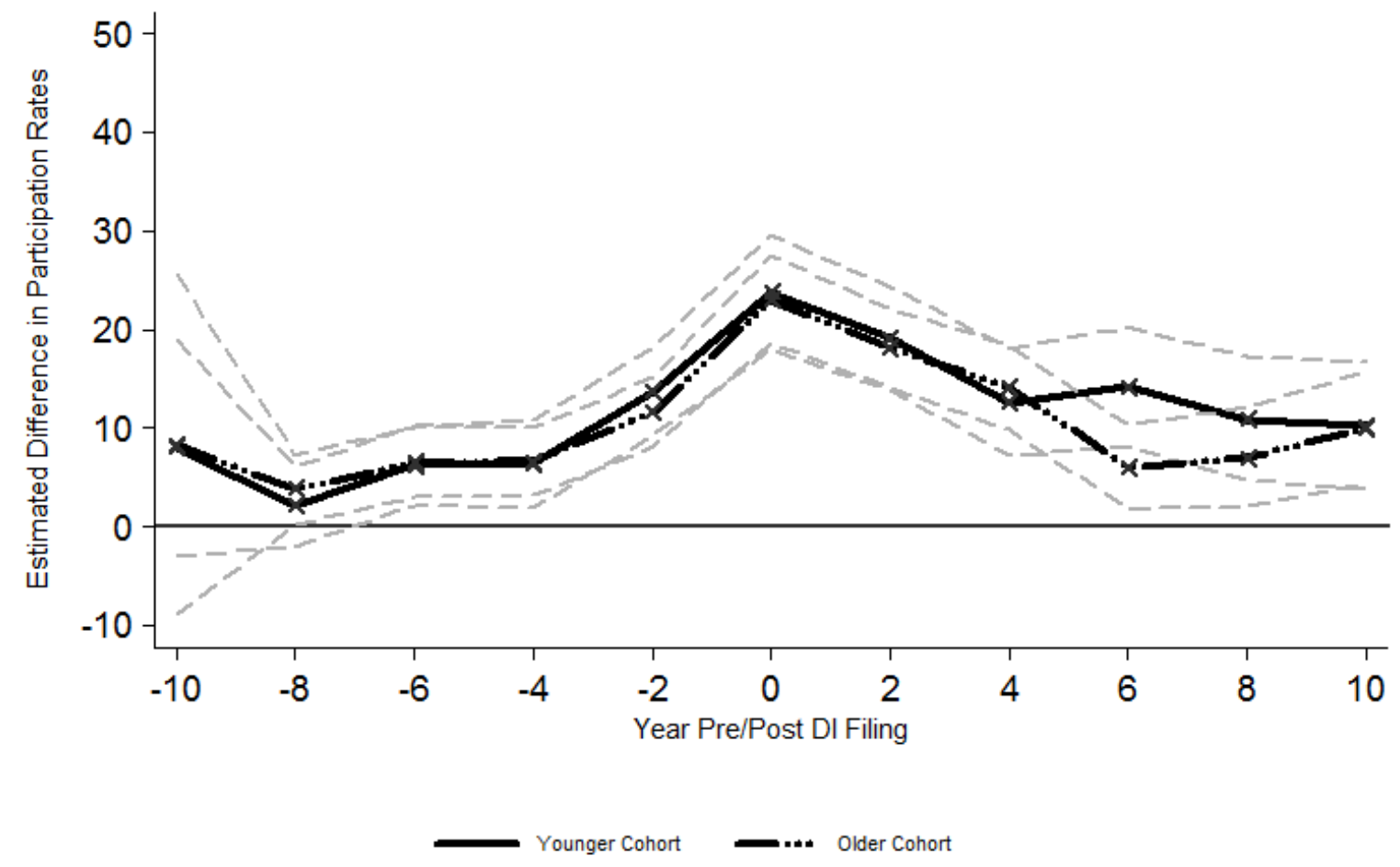

Note: The grey hatched lines represent the 95-percent confidence interval.

Figure 5: Estimated Treatment Effects By Age Cohort - Lowest Earners 

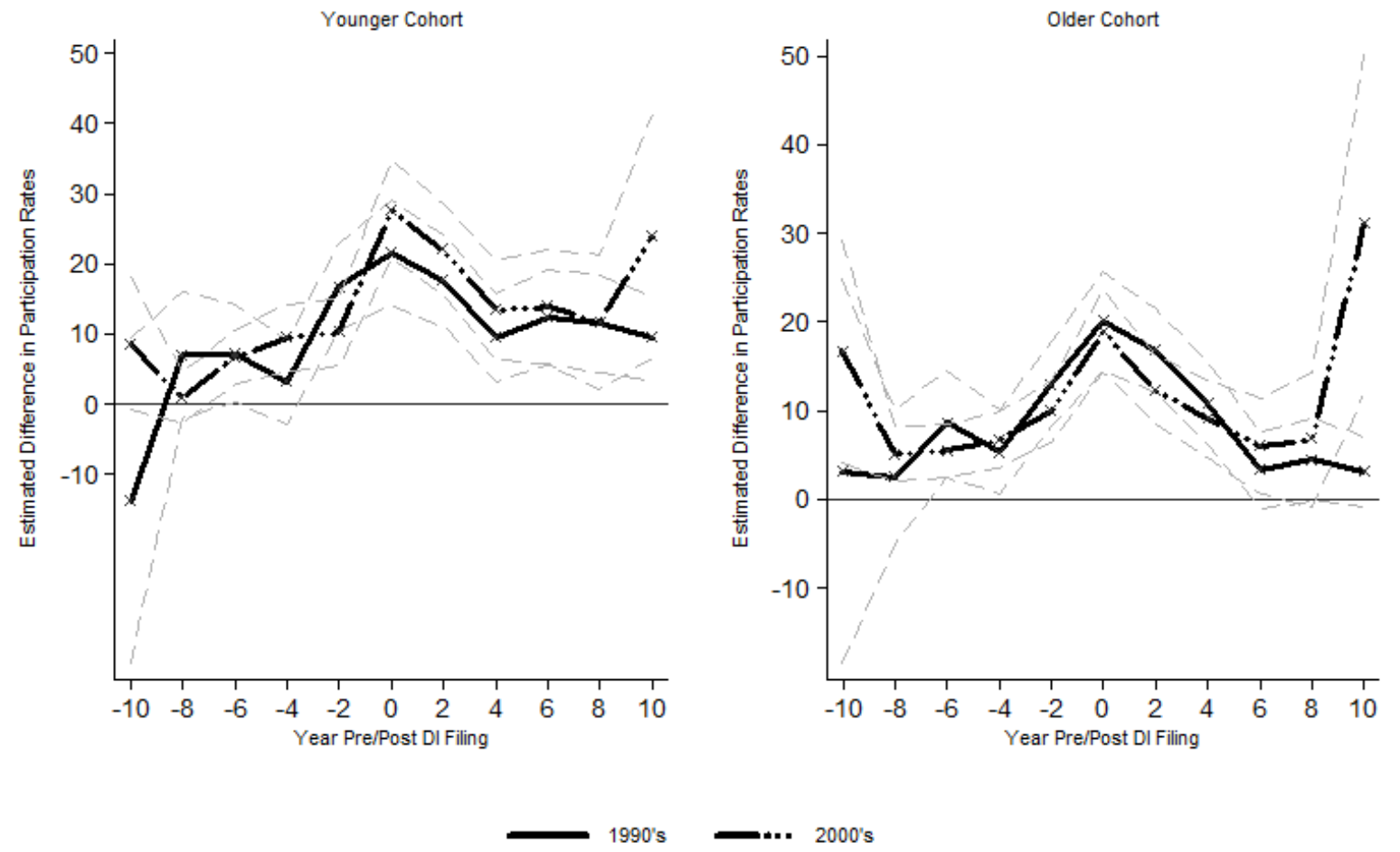

Note: The grey hatched lines represent the 95-percent confidence interval.

Figure 6: Estimated Treatment Effects By Decade of Application 


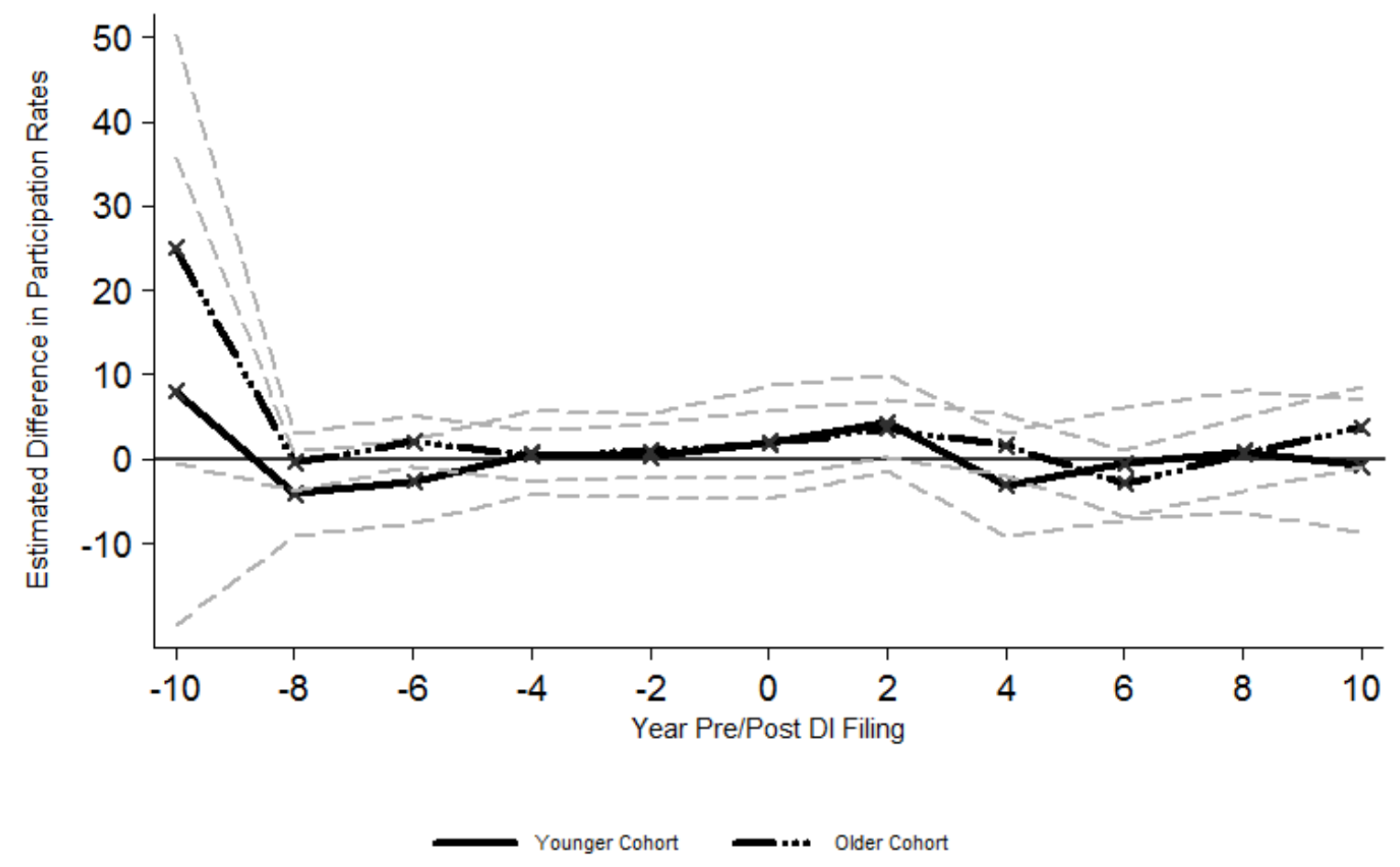

Note: The grey hatched lines represent the 95-percent confidence interval.

Figure 7: Estimated Treatment Effects with Beneficiaries as the Control Group 